\title{
Computer Processing of Chart Quadrat Maps and Their Use in Plant Demographic Studies
}

\author{
R. GERALD WRIGHT, JR. \\ Research Instructor, Natural Resource Ecology Laboratory, Colorado \\ State University, Fort Collins.
}

\section{Highlight}

Chart quadrat maps offer a unique source of data on long-term trends in grasslands. Through the use of film scanning computer systems, this information can be more easily processed and used in plant demographic studies.

There is a large and varied assemblage of data that has been collected over the years on the semiarid grasslands-information that can be valuable in studying today's important natural resource management problems. To a large extent, however, much of this information has not been sufficiently utilized because of the time involved in the effort. One such source of data of this type is that available from chart quadrat mappings.

\section{Background}

A chart quadrat usually consists of a $1 \mathrm{~m}^{2}$ field plot in which the basal cover of the vegetation is mapped by species over time, usually at yearly intervals. The quadrats are normally read utilizing a pantograph; and, since the plots are permanently marked, they can be relocated accurately and reread year after year. The data obtained are in essence maps of what has happened to the vegetation on a given piece of ground over time. These maps are usually drawn on a standard $8 \times 8$ inch form.

Because of the long time span often covered by the readings and the abundance of the records, such maps represent a valuable source of data which can be used to examine, for example, long-term plant demographic processes in response to climatic changes over time.

${ }^{1}$ Received October 23, 1971.
This paper presents a method which enables one to more easily quantify and use the information on chart quadrat maps and some examples of how these data can be used in plant demographic work.

\section{Methods}

The quadrat maps used were collected on the Journada Experimental Range, a semidesert grassland located near Las Cruces, New Mexico. The records were obtained and collated through the help and courtesy of Dr. Carlton Herbel. Chart quadrats were originally established on the Jornada range in 1915 and have been mapped each year since with the exception of a few years during the period of 1954 through 1967. The last charting was in August 1968 by the author and personnel from Colorado State and New Mexico State Universities.

There are about 90 quadrats on the Jornada Experimental Range that can be classified as longterm (greater than 30 years) and a slightly greater number that were established for short-term studies ( 5 to 30 years). All have been coded in the method described herein. Forty of the long-term quadrats have been used in the work on plant demography discussed here. Reviews of these data are included in Herbel, Dittberner, and Bickle (1970), Nelson (1934), and Paulsen and Ares (1962).

The first step in processing the data was to retrace all of the original field forms emphasizing in solid color the basal areas of the individual plants. All other pertinent information on the original forms, e.g., presence of stolons and partially or totally dead areas, was recorded and punched onto a card deck. This helped to elimi- nate much of the "noise" and artifacts which appeared on the original data and gave a clear contrasting figure. The tracings were then photographed serially on highcontrast $35 \mathrm{~mm}$ film for use as an input to a scanning device in step two.

Siegel (1967) and Harmon and Knowlton (1969) have discussed the use of film images in this form as input to one of several types of cathode-ray-tube scanning devices. The instrument in use in this study is a flying-spot scanner and is located at Argonne National Laboratory. A complete review of this system is available in Butler et al. (1964, 1966, 1967, 1968).

Briefly, there are two main components of the scanning system: a digital computer and a cathode-raytube optical scanner. The system operates by horizontally scanning each frame of film from bottom to top in a specified grid pattern through a point of light projected onto the film by the cathode-raytube and picked up by a photomultiplier. When this photomultiplier detects a change in the intensity of the transmitted light from one point on the frame to the next, the $x, y$ grid coordinates of this point are recorded on magnetic tape. This intensity change process occurs when either edge of a charted plant is encountered. The effect is that only the coordinates of the perimeters of each plant are recorded on tape. The time required to scan each frame of film varies directly with the amount of information the number of plants contained, but in general takes about 4 seconds.

The magnetic tape is then transferred to a Control Data Corp. computer (CDC-3600) where a program reconstructs the shape and position of each plant and calculates several measures described below that are descriptive of the shape and area of each plant.

The computer output is in the form of: (i) magnetic tape containing complete information on each plant per year per quadrat, 
Table 1. Mean life-spans (years), standard deviations (s) and number of occurrences (n) for principal perennial grasses on the Jornada Experimental Range. Table also contains the mean life-span as a percent of maximum longevity attained in the data and the mean life-span of those plants living more than one year as a percent of maximum attained.

\begin{tabular}{|c|c|c|c|c|c|}
\hline Species & $\begin{array}{c}\text { Mean } \\
\text { life-span }\end{array}$ & s & $\mathrm{n}$ & $\begin{array}{l}\text { Mean as } \% \\
\text { of maximum } \\
\text { life-span }\end{array}$ & $\begin{array}{l}\text { Mean of those } \\
\text { living at least } \\
\text { one year as a } \\
\% \text { of maximum }\end{array}$ \\
\hline Black grama (Bouteloua gracilis) & 2.2 & 2.4 & 6528 & 8 & 14 \\
\hline Red three-awn (Aristida longiseta) & 1.9 & 1.7 & 355 & 21 & 40 \\
\hline Mesa dropseed (Sporobolus flexuosus) & 1.7 & 1.4 & 1509 & 9 & 18 \\
\hline Poverty three-awn (Aristida divaricata) & 1.8 & 1.5 & 380 & 19 & 33 \\
\hline Ear muhly (Muhlenbergia arenacea) & 1.8 & 1.3 & 932 & 20 & 31 \\
\hline Burro grass (Scleropogon brevifolius) & 1.8 & 1.5 & 1274 & 15 & 25 \\
\hline Tobosa grass (Hilaria mutica) & 2.0 & 1.5 & 112 & 29 & 44 \\
\hline
\end{tabular}

print listing all plants plotted per year with similar information, and (iii) microfilm picturing the chart quadrat map as perceived by the scanner.

In the third and final step, the tape output is converted to punched cards for easier manipulation. Each card represents all the information calculated for a given plant in a particular year and includes: the basal area occupied by the plant (converted to $\mathrm{cm}^{2}$ ), the location coordinates of the plant on the quadrat, and six statistical moments descriptive of the shape of the plant. The scanning system cannot descriminate between species in the usual sense. If each species had a characteristic basal area growth form that is unique, then this would be possible. Lastly, information on the presence or absence of stolons and dead or partially dead areas is added into the set.

Data from the Jornada range have already undergone extensive preliminary analyses (Wright and Van Dyne, 1970). The vegetative cover on the Jornada Experimental Range is less than $5 \%$, normally occurring as bunchgrasses and small areas of sod. This fact aids in ease of scanning discrimination. The system, however, should work well for areas of up to $60 \%$ discontinuous cover. In the computer program governing the scanner, there is a direct relation between the size of the smallest plant de- tcctable and the smallest detectable distance between two separate plants. In practice, however, this has caused no problem.

\section{Demographic Analyses}

The area of study that might be defined as plant demography, the statistical study of plant populations, has been an often neglected part of plant ecology. This is principally because of the plasticity in size and reproductive capacity inherent in plants, the difficulty in isolating the individual in the population, vegetative reproduction, and factors in plant distribution (Harper, 1960, 1967). Since individuals in the population are fixed in position and these positions are rarely at random, more commonly more or less clumped, the population size is difficult to determine.

The regular charting of individual plants in permanent quadrats has generally been the best way of looking at the population changes for particular systems (Williams, 1968). However, as Williams points out, this technique is fraught with difficulty. Crucial events may occur so infrequently as to be missed in the course of the experiment, and the need for the maintenance of long-term plots contributed to the near absence of studies on plant community population changes. The result is that the question of plant longevity is often answered with little more precision than an cstimate of eternity to a few years.

Plant longevity was investigated on the Jornada quadrat data using a computer program which uses the coordinate position of each plant and searches the yearly records in a serial manner for a given quadrat. Using this approach, reliable estimates of the life-spans or more accurately the spans of existence for the major perennial grasses on the Jornada have been obtained. The mean life-spans for the eight most important species over all grazing and soil treatments are shown in Table 1. Statistical analysis has shown that soil type and grazing intensity did not have a significant effect on the plant life-spans in this data (Wright, unpublished).

Robbins (1957) has discussed the difficulties with respect to the physiological aging in plants. It is probably not unreasonable to conclude that all plants have a physiological maximum life-span which is invariant across all ranges. The mean life-span of a species is probably not fixed, but differs from the physiological maximum in response to a multitude of environmental factors. The proximity of the two measures depends in part on the success of a given species in "learning" how to cope with environmental fluctuations in order to stretch its mean life-span toward the maximum.

For the variable environment of 
Table 2. Survival probabilities for black grama on one grazing and soil treatment of the Jornada Experimental Range. Each entry represents the proportion of plants surviving from year 1 to 8 between years $i$ and $i+1$. Table shows only first eight years of age as an example of the many possible years.

\begin{tabular}{ccccccccc}
\hline \hline & \multicolumn{10}{c}{ Years of age } \\
\cline { 2 - 10 } Date & 1 & 2 & 3 & 4 & 5 & 6 & 7 & 8 \\
\hline 1915 & .379 & .583 & .571 & .750 & 1.000 & 1.000 & .500 & 1.000 \\
1916 & .125 & .455 & .429 & .500 & .667 & 1.000 & .500 & 1.000 \\
$*$ & $*$ & $*$ & $*$ & $*$ & $*$ & $*$ & $*$ & $*$ \\
1966 & .250 & 0.000 & 0.000 & 0.000 & 0.000 & 0.000 & 0.000 & 0.000 \\
1967 & 0.000 & 1.000 & 0.000 & 0.000 & 0.000 & 0.000 & 0.000 & 0.000 \\
1968 & 0.000 & 0.000 & 0.000 & 0.000 & 0.000 & 0.000 & 0.000 & 0.000 \\
\hline
\end{tabular}

* Data for the years 1917 to 1965 inclusive is available but is not included in this example.

southern New Mexico, the values listed in Table 1 give a good representation of the true mean physiological life-span of these grasses over the period of study. Table 1 also lists these means as a percent of the physiological maximum life-span of the respective species. (The maximum life-span is that achieved by at least one plant over the period of study.) The longest lived plant on any of the quadrats analyzed was one black grama clump which persisted for 27 years. Several black grama clumps persisted for 20 years. Likewise, while the longest lived mesa dropseed plant persisted for 18 years, several survived for up to 12 years. For all other species listed the maximum calculated life-span was not only much shorter but only rarely approached. These findings coincide directly with the amount of data available on each species (note the values for $\mathbf{n})$. It appears that the more data that are available, the more chance there is of finding those few long-lived plants. The amount of data available does not, however, seem to alter the mean life-spans. To illustrate the effect of environmental adaptation, the means of those plants living at least one year as a percentage of the maximum are also shown. The percentages are in many cases almost double those calculated from establishment and only point out the lower survival probabilities between the first and second age classes.

The coded quadrat data also provide an exciting avenue for examining the dynamics of the demographic changes. Dittberner (1971) recently used thesc coded data in computing life tables for treating the dynamics of change is to look at the age specific survival rates for a given species for each year. Table 2 shows an example of this type of data. Studies are now being conducted which are attempting to adjust survival matrices of this type by the population-age specific survival rates as derived from life tables and then to relate the adjusted values to climatic changes. Thus far, the results from this endeavor look promising.

\section{Literature Cited}

Butler, J. W., M. K. Butler, and A. Stroud. 1964. Automatic classification of chromosomes. I, p. 261275. In $\mathrm{K}$. Enslein [ed.] Data processing in biology and medicine, Vol. 3. Pergamon Press Inc., New York. Butler, J. W., M. K. Butler, AND A. Stroud. 1966. Automatic classification of chromosomes. II, p. 47-57. In K. Enslein [ed.] Data processing the same species. One method of in biology and medicine, Vol. 4. Pergamon Press Inc., New York.

Butler, J. W., M. K. Butler, and V. Marlzynska. 1967. Automatic analysis of 835 marmoset spreads. Argonne Nat. Lab. Tech. Mem. 140.

Butler, J. W., M. K. Butler, and A. STroud. 1968. Automatic classification of chromosomes. III, p. 231328. In $\mathrm{K}$. Enslein [ed.] Data processing biology and medicine, Vol. 5. Pergamon Press Inc., New York.

Dittberner, P. L. 1971. A demographic study of some semi-desert grassland plants. M.S. Thesis. New Mexico State Univ. 77 p.

Harmon, L. D., and K. Knowlton. 1969. Picture processing by computer. Science 164:19-23.

Harper, J. L. 1960. Factors controlling plant numbers. In J. $\mathrm{L}$. Harper [ed.] The biology of weeds. Blackwell Sci. Pub., London. 256 p.

Harper, J. L. 1967. A Darwinian approach to plant ecology. J. Ecol. 55:247-270.

Herbel, C. H., P. L. Dittberner, and T. S. Bickle. 1970. A quantitative ecology of the Jornada Experimental Range, p. I-133 to I-178. In R. G. Wright and G. M. Van Dyne [ed.] Simulation and analysis of dynamics of a semi-desert grassland. Range Sci. Dep. Sci. Ser. No. 6. Colorado State University, Fort Collins.

Nelson, E. 1934. The influence of precipitation and grazing upon black grama grass range. U.S. Dep. Agr. Tech. Bull. No. 409.

Paulsen, H. A., And F. N. Ares. 1962. Grazing values and management of black grama and tobosa grasslands and associated shrub ranges of the southwest. U.S. Dep. Agr. Tech. Bull. No. 1270.

Robbins, W. J. 1957. Physiological aspects of aging in plants. Amer. J. Bot. 44:289-295.

SIEGEL, L. 1967. Digitizing graphic records for computer analysis. IEEE Biomed. Eng., Trans. 14:7-10.

Williams, O. B. 1968. Studies in the ccology of the Riverine Plain. Australian J. Bot. 16:565-578.

Wright, R. G., ANd G. M. VAn Dyne [Ed.]. 1970. Simulation and analysis of dynamics of a semi-desert grassland. Range Sci. Dep. Sci. Ser. No. 6. Colorado State Univ., Fort Collins. $345 \mathrm{p}$. 